B. А. Рубан, А. С. Кузнечова. Предоставление государственных услуг как фактор социально-экономического развития страны

УДК 338.244

DOI 10.18101/2304-4446-2020-2-29-33

\title{
ПРЕДОСТАВЛЕНИЕ ГОСУДАРСТВЕННЫХ УСЛУГ КАК ФАКТОР СОЦИАЛЬНО-ЭКОНОМИЧЕСКОГО РАЗВИТИЯ СТРАНЫ
}

() Рубан Владимир Алексеевич

доктор экономических наук, профессор

\section{(C) Кузнецова Анна Сергеевна}

обучающийся

Сибирский государственный университет путей сообщения

Россия, 630049, г. Новосибирск, ул. Дуси Ковальчук, 191

E-mail: gmu@sgups.stu.ru

В статье рассмотрены и раскрыты проблемы предоставления государственных услуг и повышения их качества и доступности для граждан, а также анализ административной реформы и федерального законодательства в сфере организации предоставления государственных услуг, анализ количества электронных обращений в Федеральную службу государственной регистрации, кадастра и картографии (Росреестр) по Новосибирской области. Указаны причины увеличения сроков предоставления государственных услуг. Описана система Новосибирской области «Межведомственная автоматизированная информационная система», созданная на платформе Smart-Route (АИС МАИС). Рассмотрены виды межведомственного информационного взаимодействия, их недостатки и преимущества. Описан основной инструмент урегулирования предоставления государственных и муниципальных услуг - административный регламент. Предложены мероприятия по повышению качества и доступности предоставления государственных услуг.

Ключевые слова: государственные услуги; органы государственной власти; повышение качества и доступности государственных и муниципальных услуг; межведомственное информационное взаимодействие; совершенствование; административный регламент; единая запросно-ответная система.

\section{Для цитирования}

Рубан В. А., Кузнецова А. С. Предоставление государственных услуг как фактор социально-экономического развития страны // Вестник Бурятского государственного университета. Экономика и менеджмент. 2020. № 2. С. 29-33.

Экономическое развитие страны напрямую зависит от качества государственного управления. В настоящее время рынок предъявляет требования уже более высокого уровня к эффективности государственного аппарата и самой исполнительной власти.

Государственные услуги, а именно их качество и доступность гражданам, характеризуют состояние социально-экономического развития страны. Одним из важнейших приоритетов развития Российской Федерации является повышение качества и доступности государственных услуг.

Административной реформой был принципиально изменен подход к оказанию государственных услуг. Раньше, чтобы получить ту или иную государ- 
ственную услугу, заявителю нужно было самостоятельно собрать определенный пакет документов, для чего следовало посетить много организаций. Далее заявитель был вынужден передавать документы между организациями сам, а иногда даже между должностными лицами внутри одних и тех же организаций. Иначе говоря, межведомственное взаимодействие должностных лиц осуществлялось с участием заявителя. В связи с этим совершенствование межведомственного информационного взаимодействия рассматривалось административной реформой как одно из главных направлений повышения качества и доступности государственных и муниципальных услуг.

Доступность государственных услуг повышается благодаря межведомственному информационному взаимодействию посредством сокращения количества запрашиваемых организацией документов, необходимых для предоставления услуги. Органы государственной власти могут самостоятельно получить недостающие документы и сведения.

Федеральный закон от 27 июля 2010 г. № 210-Ф3 «Об организации предоставления государственных и муниципальных услуг» ${ }^{1}$ установил требования к организации межведомственного взаимодействия. Данные требования были внесены в Концепцию снижения административных барьеров и повышения доступности государственных и муниципальных услуг на 2011-2013 гг., утвержденную распоряжением Правительства Российской Федерации от 10 июня 2011 г. № 1021-р².

В настоящее время в Российской Федерации используются такие виды межведомственного информационного взаимодействия, как:

1) традиционный бумажный документооборот - передача документов между сотрудниками организаций;

2) системы электронного документооборота (СЭД), электронная почта передача документов в электронном виде;

3) унифицированное информационное взаимодействие - передача документов внутри информационных систем;

4) интерактивные запросные приложения - используются некоторыми ведомствами в качестве пользовательских электронных сервисов, размещенных на официальных сайтах органов власти или ведомственных электронных порталах.

Сроки оказания государственной услуги увеличиваются из-за бумажного документооборота при межведомственном взаимодействии, происходит увеличение нагрузки на специалистов и постоянный рост объема почтовой корреспонденции.

По мнению авторов, от уровня межведомственного взаимодействия зависит качество и доступность государственных услуг и именно в этой сфере многие

1 Об организации предоставления государственных и муниципальных услуг: федеральный закон от 27.07.2010 № 210-Ф3 (последняя редакция). Доступ из справ.-прав. системы «Консультант Плюс». URL: http://www.consultant.ru/document/ cons_doc_LAW_103023/ (дата обращения: 20.03.2020).

${ }^{2}$ Об утверждении Концепции снижения административных барьеров и повышения доступности государственных и муниципальных услуг на 2011-2013 годы и Плана мероприятий по реализации указанной Концепции: распоряжение Правительства РФ от 10.06.2011 № 1021-p. Доступ из справ.-прав. системы «Консультант Плюс». URL: http://www.consultant.ru/document/cons_doc_LAW_115467/ (дата обращения: 20.02.2020). 
B. A. Рубан, А. С. Кузнецова. Предоставление государственных услуг как фактор социально-экономического развития страны

проблемы еще не решены. Единые образцы запрашиваемых документов до сих пор не разработаны во многих государственных органах власти, в которые отправляется межведомственный запрос. Это влечет за собой противоречие действующим нормативно-правовым актам, так как запрос содержит информацию, которая не подлежит выдаче. В межведомственных запросах существует проблема неполной или неточной информации, чтобы выполнить данный запрос, требуется дополнительное время для обработки документов, а это приводит к увеличению сроков предоставления государственной услуги.

На всей территории Российской Федерации, в каждом органе исполнительной власти и организации, предоставляющей услуги населению, отсутствует единая запросно-ответная система. В настоящее время данная система находится в стадии разработки. Так, например, на территории Новосибирской области проходит тестирование подсистема «Конструирование запросов» государственной информационной системы Новосибирской области «Межведомственная автоматизированная информационная система» (на платформе Smart-Route) (АИС МАИС). Данная подсистема относится к региональному сегменту. C ее помощью можно сделать запросы в Федеральную налоговую службу, МЧС России, Роспотребнадзор и Росреестр.

Главной проблемой, требующей особого внимания, остается некорректная работа электронных порталов. Сервисы межведомственного взаимодействия продолжают модернизировать. В настоящее время наблюдаются снижение качества и увеличение сроков предоставления услуг из-за постоянных обновлений систем, которые, в свою очередь, не решают возникающих проблем и ошибок.

Значительное влияние на инвестиционную привлекательность Новосибирской области, как и других регионов России, оказывает уровень качества предоставления государственных услуг по регистрации прав и постановке объектов недвижимости на кадастровый учет в электронном виде.

Количество электронных обращений новосибирцев за получением услуг Росреестра увеличивается с каждым годом. В 2019 г. в электронной форме поступило почти 67 тысяч заявлений о регистрации прав, около 10 тысяч заявлений о постановке объектов на кадастровый учет и свыше 6,5 тысячи заявлений на оформление недвижимости по единой процедуре - одновременно кадастровый учет и регистрация прав. В сравнении с 2018 г. рост электронных обращений в Новосибирской области составил почти 1,5 раза. Поставлена задача по увеличению в 2020 г. доли услуг, предоставляемых всем категориям заявителей в электронном виде, до $80 \%$.

С целью совершенствования предоставления государственных услуг Управлением Росреестра по Новосибирской области в марте и июне 2020 г. запланировано проведение дней электронных услуг, в рамках которых будут организованы встречи с профессиональными участниками рынка недвижимости (застройщиками, банками, риелторскими сообществами и т. д.) и органами местного самоуправления Новосибирской области в формате обучающих семинаров и мастерклассов.

Правительством Новосибирской области ежегодно разрабатываются и утверждаются мероприятия, направленные на улучшение показателей инвестиционного климата региона, одним из исполнителей которых является Управление Ро- 
среестра по Новосибирской области. Росреестр регулярно проводит исследования вовлеченности граждан и представителей бизнес-сообщества в процесс цифровизации государственных услуг.

Качество услуг является социально-технико-экономической характеристикой и определяется государственными стандартами, которые учитывают требования потребителей. При этом необходимо иметь возможность обеспечить базовый уровень качества, в частности, технического соответствия и удовлетворения запросов индивидуумов [2].

Принятие административных регламентов стало основным инструментом урегулирования предоставления государственных и муниципальных услуг. Административный регламент - нормативно-правовой акт государственного органа исполнительной власти или органа местного самоуправления, устанавливающий сроки и последовательность административных процедур и административных действий органа власти, а также порядок их взаимодействия с физическими или юридическими лицами [1].

Постановлением Правительства Российской Федерации от 16 мая 2011 г. № 373 были утверждены новые Правила разработки и утверждения административных регламентов исполнения государственных функций и предоставления государственных услуг, а также Правила проведения экспертизы проектов административных регламентов предоставления государственных услуг ${ }^{1}$.

Благодаря административным регламентам систематизировался перечень полномочий органов государственной власти, исправились неточности в законодательстве Российской Федерации, упорядочились административные процедуры, а в отдельных случаях удалось исключить избыточные действия. Административным регламентом установлены требования к обслуживанию и комфортности граждан, а также персональная ответственность должностных лиц и возможность досудебного обжалования их действий (бездействия).

Повышению качества предоставления государственных услуг будут способствовать проведение мероприятий для населения в части использования электронных сервисов, на которых можно получить государственные услуги и повышение качества подготовки специалистов, осуществляющих процесс предоставления государственных услуг населению.

Таким образом, для совершенствования межведомственного взаимодействия в процессе предоставления государственных услуг, по мнению авторов, необходимо:

1) обновить и усовершенствовать программно-техническое обеспечение электронных сервисов для стабилизации их работы;

2) установить единый регламент работы информационных систем и сервисов;

3) повысить качество вводимых данных за счет внедрения современных информационных средств;

4) повысить уровень квалификации специалистов, которые задействованы в процессе межведомственного взаимодействия;

${ }^{1} \mathrm{O}$ разработке и утверждении административных регламентов исполнения государственных функций и административных регламентов предоставления государственных услуг: постановление Правительства Российской Федерации от 16.05.2011 № 373. Доступ из справ.-прав. системы «Консультант Плюс». URL: http://www.consultant.ru/document/ cons_doc_LAW_114205 (дата обращения: 20.02.2020). 
5) обеспечить более тесное взаимодействие между участниками межведомственного взаимодействия для решения проблем с предоставлением запрашиваемой информации, благодаря чему произойдет оптимизация процесса оказания государственных услуг.

Широкое внедрение электронной формы предоставления государственных услуг выведет систему предоставления государственных услуг на новый качественный уровень, что, в свою очередь, повлияет на повышение уровня социально-экономического развития страны.

\title{
Литература
}

1. Наумов С. Ю. Государственное и муниципальное управление. М.: Ай Пи Эр Медиа, 2012. $554 \mathrm{c.}$

2. Рубан В. А. Механизмы инвестиционного развития в социальных транзитивных отраслях // Проблемы современной экономики: евразийский междунар. науч.-практ. журнал. 2011. № 4(40). С. 295-298.

\section{PROVISION OF PUBLIC SERVICES AS A FACTOR OF THE COUNTRY'S SOCIO-ECONOMIC DEVELOPMENT}

\author{
Vladimir A. Ruban \\ Dr. Sci. (Econ.), Prof. \\ Anna S. Kuznetsova \\ Student
}

Siberian State Transport University

191 Dusi Kovalchuk St., Novosibirsk 630049, Russia

E-mail: gmu@sgups.stu.ru

The article discusses the problems of providing public services and improving their quality and accessibility for citizens. We have analyzed the administrative reform and federal legislation in the field of public services provision, as well as the number of electronic appeals of citizens to the Federal Service for State Registration, Cadastre and Cartography (Rosreestr) in Novosibirsk Oblast. The article identifies the causes of increasing the period for provision of public services. We have described the "Interagency Automated Information System" of Novosibirsk Oblast created on the Smart-Route platform. The types of interagency information interaction, their disadvantages and advantages are considered. We consider the administrative regulations as main tools for regulating the provision of state and municipal services, and proposed the measures to improve the quality and accessibility of public services.

Keywords: public services; governmental authorities; improving the quality and accessibility of state and municipal services; interdepartmental information exchange; improvement; administrative regulations; single inquiry-response system. 